\title{
Epidemiology of Trauma with Analysis of 138.352 Patients: Trends of a Single Center
}

\author{
Kemal Tekeşin 1, (1) Fatih Başak', Abdullah Şişik', (1) Yahya Kemal Çalışkan² \\ ${ }^{1}$ Department of General Surgery, University of Health Science, Umraniye Training and Research Hospital, Istanbul, Turkey \\ ${ }^{2}$ Department of General Surgery, University of Health Science, Kanuni Training and Research Hospital, Istanbul, Turkey
}

\begin{abstract}
Introduction: The analysis of the epidemiology of trauma is important to determine the needs of hospitals and develop treatment strategies. This study aimed to investigate the epidemiology of trauma in a hospital sample that accepts a large number of trauma patients.

Methods: Between 2009 and 2015, trauma patients admitted to the hospital emergency department were retrospectively screened according to the ICD-10 system. The trauma mechanisms were grouped as falls on the level/from height, injury by object, pedestrian/cyclist injuries, vehicle collisions, penetrating stab injuries, gunshot wounds, and assault. Age, gender distribution of patients, and death information were recorded. In the analysis of the data, t-test and chi-square test were used for the comparison with descriptive statistics. $P<0.05$ was accepted as significant.

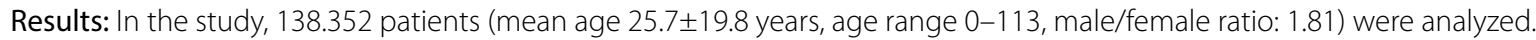
Falls on the level/from height was the most prominent cause of trauma ( $n=76.636,55.4 \%$ ). Male gender was predominant in all injury mechanisms and in all age group except over 60 years $(p<0.001)$. The most common injury mechanisms that resulted in death were falls on the level/from height, vehicle collision, and pedestrian/cyclist injury with mortality rates of $0.09,0.08$, and 0.07 , respectively $(p<0.001)$.

Discussion and Conclusion: Our study found that in emergency service trauma applications, fall-crash and traffic accidents were the two most common mechanisms. The frequency of trauma mechanisms should be considered in the emergency service continuous training programs. Social measures for trauma mechanisms leading to more deaths and trainings of people based on age-gender, where trauma mechanisms are more common, will reduce the morbidity and mortality rates caused by trauma.

Keywords: Epidemiology; mortality rate; trauma.
\end{abstract}

$E^{p}$ pidemiology is the study of health and disease in populations, the study of the patterns, causes, and effects of health and disease conditions in populations. It is the cornerstone of public health, and shapes policy decisions and targets for preventive healthcare. The rationale of epidemiology offers that effective control of disease must be planned by within individual countries; however, injury has a different impact in every community regardless of demographics ${ }^{[1-3]}$.

Trauma is a major cause of death and a worldwide problem with wide-ranging consequences for individuals ${ }^{[4,5]}$. Analyzing the epidemiology of trauma helps to develop treat-

Correspondence (İletişim): Fatih Başak, M.D. Umraniye Egitim ve Arastirma Hastanesi, Saglik Bilimleri Universitesi, Genel Cerrahi Anabilim Dali, İstanbul, Turkey

Phone (Telefon): +90 5055034571 E-mail (E-posta): fatihbasak@gmail.com

Submitted Date (Başvuru Tarihi): 22.05.2019 Accepted Date(Kabul Tarihi): 26.05.2019

Copyright 2019 Haydarpaşa Numune Medical Journal

OPEN ACCESS This is an open access article under the CC BY-NC license (http://creativecommons.org/licenses/by-nc/4.0/). 
ment strategy, to reduce disability, to provide better care, to prevent mortality, and to establish a precise intervention system. However, the disregard of trauma epidemiology limits the improvement of these trauma management systems ${ }^{[6,7]}$.

We aimed to examine the epidemiology of trauma within a local community in Turkey through data from one emergency center.

\section{Materials and Methods}

We designed a descriptive cohort study conducted at a tertiary education and research hospital. The local Ethics Committee approved the study (UEAH-2015-87). The study was performed in accordance with the ethical standards laid down in the 1964 Declaration of Helsinki and its later amendments.

This study is a retrospective analysis of the prospectively collected register of patients held by the hospital records. The hospital register codes the mechanism of trauma using the International Classification of Disease version 10 (ICD-10). Trauma patients were selected by ICD-10 codes related with trauma. Trauma patients admitted to emergency department between January 1, 2009, and Dec 31,2015 , were included in the study. The mechanisms of trauma were consolidated into seven broad categories: falls on the level/from height, injury by object, pedestrian/cyclist injuries, vehicle collisions, penetrating stab injuries, gunshot wounds, and assault. Cases relating to poisoning, burns, chemical injury, drowning, and suicide were excluded. The following data was collected for each patient: basic demographic data (age and gender), mechanism of trauma, and death.

\section{Statistical Analysis}

Statistical calculations were performed using IBM SPSS 22 (IBM SPSS, USA). Variables are expressed as mean \pm standard deviations (SD) or as medians (interquartile range) depending on their distribution. Categorical variables were expressed as frequencies and percentages. The chi-square test was used to compare continuous parametric variables. The t-test was used to compare parametric variables with normal distribution. The statistical results were presented with a $95 \%$ confidence interval. The differences were considered statistically significant if the P-value was less than 0.05 .

\section{Results}

A total of 149.582 trauma patients were reviewed for eligibility. After exclusion of 11.230 patients, 138.352 patients were enrolled in the study. The mean age was $25.7 \pm 19.8$ years (range $0-113$ ), and male to female ratio was 1.8:1. The age and gender distribution were investigated, and they are summarized in Figure 1. Male gender was predominant in all age groups except over 60 years.

Injury mechanisms are summarized in Table 1. Falls on the level/from height was the most prominent cause of trauma $(n=76.636,55.4 \%)$. The mean age of the patients was different between injury mechanisms. Especially age of patients with gunshot wounds, vehicle collision, and assault was over 30 years, and they were older than the patients with other injury mechanisms $(p<0.001)$ (Fig. 2). Male gender was predominant in all injury mechanisms, and male to female ratio was 9.9 in patients with gunshot wounds as the highest value at all $(p<0.001)$.

A total of $225(0.16 \%)$ patients died due to related trauma.

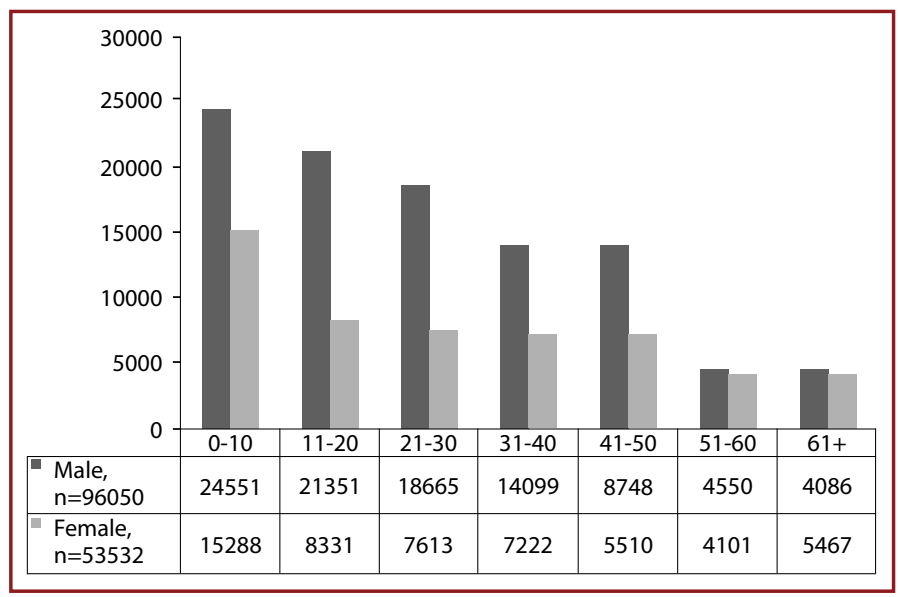

Figure 1. Demographic characteristics of the trauma patients.

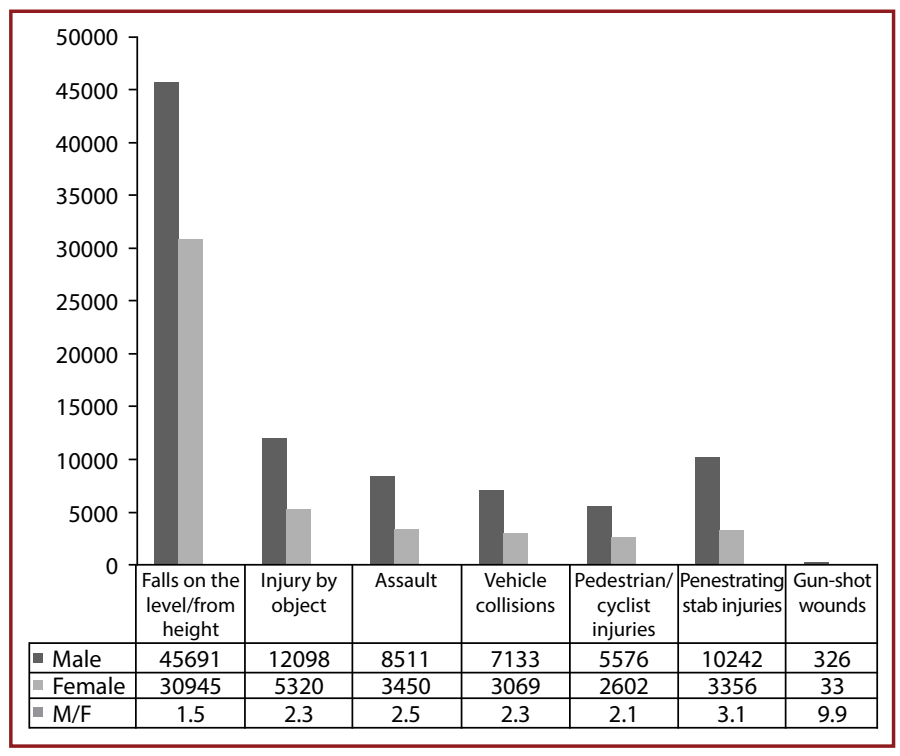

Figure 2. Demographic characteristics of the trauma patients according to injury mechanisms. 
More patients died due to fall on the level/from height, vehicle collision, and pedestrian/cyclist injury with mortality rates of $0.09 \%, 0.08 \%$, and $0.07 \%$, respectively $(p<0.001)$. Mortality rates in the patients with injury by object and assault were the lowest of all the mechanisms, $0.004 \%$ and $0.001 \%$, respectively.

\section{Discussion}

Trauma constitutes an important and rising worldwide problem. The number of injuries other than violence is rising as the country industrializes. The expansion of transportation and industrialization causes an increase in the number of trauma cases, for example, motor vehicle accidents, people falling, object crashing, or penetrating injury at industrial sites ${ }^{[1,2]}$. Trauma incidence and trends vary worldwide. Actually, trauma data collected by national statistics use ICD code, which is taxonomy with limited descriptions of injury severity ${ }^{[1]}$. In this study, we reviewed admissions of 149.582 trauma patients between 2009 and 2015. The number of cases reviewed can be accepted as sufficient, but this is the data of single center; therefore, it may not be generalized to other countries. In this study, ICD diagnostic code system is used to search the patient's records for the trauma like national statistics worldwide.

The abbreviated injury scale (AIS) dictionary has a greater level of detail with a severity score between 1 and 6 . It has over 2000 injury codes and allocates to the every injury ${ }^{[8]}$. These scores have to be summated into the injury severity score (ISS) for each individual patient ${ }^{[9]}$. In most of studies, AIS/ISS taxonomy has been used to define injury incidence. Severe injury is mentioned if ISS is more than 15. In Europe, most of trauma admissions were not severe and have lower ISS (range 4-9) mostly due to isolated limb fractures in children or the elderly (falls). The annual rates of death and severe injury (ISS>15) vary in Europe from 25 to 52.2 per $100.000^{[10,11]}$. We evaluated epidemiology of trauma with limited descriptions of injury severity. Main obligatory issue for this was the nature of our retrospective study design.

The reported mortality rate of injury in 2000 was 83 per 100.000 of the population worldwide. The highest mortality rates from injury have been documented in the lowincome nations in Eastern Europe, and the lowest rates in North America and Western Europe ${ }^{[12]}$. In our study, we detected higher mortality rate $(0.16 \%)$ than reported ratio for worldwide.

Most of the trauma patients who visit emergency, had hospitalizations and fatalities, are persons under 45 years 
of age. After 65 years, patients are at higher risk of injuries needing hospitalization or resulting in fatality. Trauma increases after the age of 60 due to the body weakening and lack of activities ${ }^{[8]}$. The trauma distribution of according to age shown in our study is similar with that of other studies.

There is changing frequency about gender according to the age as a risk factor for trauma. Reports showed that up to age 65 years, male gender is a risk; after that age, female gender is a risk factor ${ }^{[10,11]}$. Moshiro et al. ${ }^{[13]}$ and WHO $[12,14]$ stated that motor vehicle accidents and falls seem more often with men than with women. In our study, we detected gunshot wounds ( 9.9 fold) and penetrating stab injuries ( 3.1 fold) more often in men than women.

In low- and mid-income nations, which make up $85 \%$ of the world, $11 \%$ of all handicap balanced life years are because of injury. Especially, understanding the study of disease trending of injury investigates hazard factors, to create treatment technique, to decrease incapacity, to avoid mortality. In any case, the absence of injury the study of disease transmission information restrains the development of these injury administration frameworks ${ }^{[5,6]}$.

A large portion of the injury instruments in our information were blunt injury, fall-down wounds, and vehicle-related injury $(90.8 \%)$. Thus in general, fall-down wounds and vehicle-related injury will prevail ${ }^{[15,16]}$. Motor vehicle injuries are among the most noteworthy driving reasons for death and inability and are a noteworthy reason for injury patients in general wellbeing. Smashed driving, sleepy driving, and imprudent driving are a few instances of the reasons for engine vehicle mishaps, and every one of them is unmistakable in young fellows and women in general ${ }^{[17]}$. Falldown wounds are additionally among the most elevated driving reasons for obtuse injury; these kinds of wounds are brought about via inconsiderateness or self-destructive aims. The damage systems referenced above are medical issues that can be counteracted by wellbeing instruction by advancing a sheltered situation and proceeding with wellbeing training ${ }^{[18,19]}$. In our study, fall-crash and traffic accidents were the two most common mechanisms with ratio of $68 \%$ of all trauma patients.

\section{Conclusion}

In conclusion, as we continue to use more efficient diagnostic methods and tools to provide more efficient and higher quality patient care, we must advance to evaluate the epidemiology of trauma to better prevent it, and more effectively manage it.
Ethics Committee Approval: Umraniye Education and Research Hospital, Ethical Committee (19.11.2015, UEAH-2015-87).

Peer-review: Externally peer-reviewed.

Authorship Contributions: Concept: K.T., F.B.; Design - K.T., A.S.; Supervision - F.B., Y.K.C.; Materials - K.T., Y.K.C.; Data collection / processing - F.B., A.Ş.; Analysis and/or interpretation - F.B., Y.K.Ç.; Literature review: F.B., A.Ş.; Writing - A.Ş., Y.K.Ç.; Critical review K.T., Y.K.Ç.

Conflict of Interest: None declared.

Financial Disclosure: The authors declared that this study received no financial support.

\section{References}

1. Fiona E, Lecky, Bouamra O, Woodfordn M, Alexandrescu R, O'Brien SJ. Damage Control Management in the Polytrauma Patient. In: Hans-Christoph Pape, Andrew Peitzman, C. William Schwab, Peter V. Giannoudis, editors. Epidemiology of Polytrauma. Springer; 2010. p. 13-24.

2. Krug EG, Sharma GK, Lozano R. The global burden of injuries. Am J Public Health 2000;90:523-6. [CrossRef]

3. Murray CJ, Lopez AD. Alternative projections of mortality and disability by cause 1990-2020: Global Burden of Disease Study. Lancet 1997;349:1498-504. [CrossRef]

4. James A. Chambers MD, MPH \& TM. Epidemiology of Trauma. In: Alexander L. Eastman, David H. Rosenbaum, Erwin R. Thal, editors. Parkland Trauma Handbook. 3th edition. Dallas: 2009. p. 1-4.

5. Gross CP, Anderson GF, Powe NR. The relation between funding by the National Institutes of Health and the burden of disease. N Engl J Med 1999;340:1881-7. [CrossRef]

6. Lagarde E. Road traffic injury is an escalating burden in Africa and deserves proportionate research efforts. PLoS Med 2007;4:e170. [CrossRef]

7. Hofman K, Primack A, Keusch G, Hrynkow S. Addressing the growing burden of trauma and injury in low- and middle-income countries. Am J Public Health 2005;95:13-7. [CrossRef]

8. Committee on injury scaling, Association for the Advancement of Automotive Medicine. The Abbreviated Injury Scale. 1990 Revision. Update 98. Des Plaines, Illinois: 1990.

9. Baker SP, O'Neill B, Haddon W Jr, Long WB. The injury severity score: a method for describing patients with multiple injuries and evaluating emergency care. J Trauma 1974;14:187-96.

10. Liener UC, Rapp U, Lampl L, Helm M, Richter G, Gaus M, et al. Incidence of severe injuries. Results of a population-based analysis. [Article in German] Unfallchirurg 2004;107:483-90.

11. Di Bartolomeo S, Sanson G, Michelutto V, Nardi G, Burba I, Francescutti C; Regional Study-Group on Major Injury. Epidemiology of major injury in the population of Friuli Venezia Giulia-Italy. Injury 2004;35:391-400. [CrossRef]

12. Peden M, McGee K, Sharma G. The Injury Chart Book: a Graphical Overview of the Global Burden of Injuries. Geneva: World Health Organization; 2002.

13. Moshiro C, Heuch I, Astrøm AN, Setel P, Hemed Y, Kvåle G. In- 
jury morbidity in an urban and a rural area in Tanzania: an epidemiological survey. BMC Public Health 2005;5:11. [CrossRef]

14. World Health Organization. The World Health Report 2003: Shaping the Future. Geneva: World Health Organization; 2003.

15. Bulut M, Koksal O, Korkmaz A, Turan M, Ozguc H. Childhood falls: characteristics, outcome, and comparison of the Injury Severity Score and New Injury Severity Score. Emerg Med J 2006;23:540-5. [CrossRef]

16. Lallier M, Bouchard S, St-Vil D, Dupont J, Tucci M. Falls from heights among children: a retrospective review. J Pediatr Surg 1999;34:1060-3. [CrossRef]
17. Matthews ML, Moran AR. Age differences in male drivers' perception of accident risk: the role of perceived driving ability. Accid Anal Prev 1986;18:299-313. [CrossRef]

18. Scheffer AC, Schuurmans MJ, van Dijk N, van der Hooft T, de Rooij SE. Fear of falling: measurement strategy, prevalence, risk factors and consequences among older persons. Age Ageing 2008;37:19-24. [CrossRef]

19. Demircan A, Keles A, Gurbuz N, Bildik F, Aygencel SG, Dogan $\mathrm{NO}$, et al. Forensic emergency medicine - six-year experience of 13823 cases in a university emergency department. Turk J Med Sci 2008;38:567-75. 